\title{
ORGANIZAÇÃO E PRODUTIVIDADE NA INDÚSTRIA SIDERÚRGICA BRASILEIRA
}

\section{YOLANDA FERREIRA BALCÃ ${ }^{*}$}

O Brasil ocupa posição de liderança na América Latina na produção do aço em lingotes. Em 1963 das usinas brasileiras saíram $40 \%$ do aço em lingotes produzido na América Latina, enquanto que o México, a Argentina, o Chile e a Venezuela produziram no mesmo ano $29,13,8$ e $6 \%$, respectivamente, da produção total. Na América do Sul sòmente o Brasil produz aço LD e no Brasil se localizam 10 das 18 usinas integradas de aço da América do Sul.

Mas êsses dados que, à primeira vista, poderiam indicar um futuro venturoso e sem percalços para a indústria siderúrgica nacional, não poderão ter significado se não se examinarem detidamente os aspectos técnicos e orgânicos de funcionamento de nossas emprêsas. Por êles poderá ser aquilatada a real capacidade de concorrência e desenvolvimento da indústria nacional de aço e, portanto, sua sorte futura.

Como parte de estudo patrocinado pela "Organização dos Estados Americanos", através do "Centro Interamericano de Ciências Administrativas", com o objetivo de levantar dados sôbre a produtividade, a situação da mão-de-obra, as técnicas de vendas e a administração geral da indústria siderúrgica nacional, nossa atenção se dirigiu exatamente

\footnotetext{
* Professôra-Adjunta do Departamento de Administração Geral e Relaçōes Industriais, da Escola de Administração de Emprêsas de São Paulo, da Fundação Getúlio Vargas.
} 
para as características de organização das emprêsas que foram objeto da pesquisa. Pela natureza dos dados que levantamos, cremos poder chegar a algumas conclusões sôbre a estrutura orgânica em que estão assentadas as emprêsas pesquisadas e, por inferência, sôbre suas condições de concorrência e crescimento.

Para tanto, partiremos da descrição das características gerais das emprêsas pesquisadas e dos aspectos de administração geral e de organização da produção de cada emprêsa.

\section{AS EMPRESSAS PESQUISADAS}

As oito usinas integradas incluídas no levantamento estão localizadas na região Centro-Sul do País, isto é, nos Estados de Minas Gerais, Rio de Janeiro e São Paulo, e apresentam as características gerais constantes do Quadro 1 .

QUADRO 1: Características Gerais das Emprêsas Pesquisadas

\begin{tabular}{|c|c|c|c|}
\hline USINA & $\begin{array}{c}\text { Data } \\
\text { aproximada } \\
\text { de fundação } \\
(\text { década })\end{array}$ & $\begin{array}{c}\text { Número } \\
\text { aproximado } \\
\text { de operários } \\
\text { em } 1964\end{array}$ & $\begin{array}{c}\text { Propriedade } \\
\text { do capital }\end{array}$ \\
\hline A. & 1920 & 2.200 & $100 \%$ privado \\
\hline B. & 1930 & 2.000 & $100 \%$ privado \\
\hline & & & $100 \%$ privado \\
\hline D. & 1930 & 2.000 & $100 \%$ privado \\
\hline E. . & 1940 & 4.900 & $100 \%$ público \\
\hline F & 1950 & 4. 700 & $100 \%$ privado \\
\hline G. & 1920 & 7.700 & $100 \%$ privado \\
\hline & 1940 & 14.200 & $\begin{array}{ll} & \text { estrangeiro } \\
90 \% & \text { público }\end{array}$ \\
\hline
\end{tabular}

Como se vê no Quadro 1, três das usinas ( $\mathrm{A}, \mathrm{C}, \mathrm{G}$ ) têm mais de quarenta anos de existência, duas $(B, D)$ mais de trinta, duas $(E, H)$ mais de vinte e sòmente uma tem cêrca de quinze. 
Consideradas em comparação às usinas norte-americanas e européias, essas emprêsas são relativamente novas, o que, em princípio, dada a obsolescência rápida do equipamento do setor, deveria constituir uma vantagem. Parece, entretanto, que a renovação de equipamento da indústria nacional não é tão rápida quanto a das estrangeiras mencionadas .

Os dados em que baseamos nossa análise são relativos ao quinquiênio de 1960 a 1964 e foram obtidos em respostas das emprêsas pesquisadas a quesitos de um questionário especial, em entrevistas com os dirigentes das emprêsas e de fontes secundárias sôbre os aspectos que interessavam ao estudo.

\section{ADMINISTRAÇÃO GERAL DAS EMPRESAS PESQUISADAS}

Examinaremos cada emprêsa separadamente, pois, a par das características gerais que em alguns casos se assemelham, tôdas têm sua história particular e sua fisionomia própria do ponto de vista da administração.

A Emprêsa $A$

A Emprêsa $A$ é uma sociedade fechada, propriedade de família. Todos os diretores são membros da família, mas nenhum dêles tem formação profissional superior. Os administradores de nível médio-superior (gerentes) são recrutados entre os parentes da família, mas, neste caso, têm, em sua grande maioria, formação em Engenharia, Direito e outras escolas superiores. A emprêsa proporciona a seus administradores oportunidades de aperfeiçoamento ou estágios em congêneres estrangeiras, mas sem plano sistemático.

Muitos dos atuais administradores começaram sua carreira há dois ou três decênios na emprêsa, sendo considerados como "pertencentes" à família. Êsses administradores acentuam sua admiração pelo fundador (presidente) da emprêsa, insistindo sôbre êsse aspecto de administração (tìpicamente paternalista) que consideram muito positivo. 
A emprêsa não tem organograma e nunca elaborou um manual de organização ou de procedimentos para os diversos departamentos. Mas nela é ressaltado que a falta de organização é compensada pela maneira "democrática e aberta" com que são ventilados os assuntos e tomadas as decisões na gerência e na diretoria.

A comunicação com os superiores hierárquicos é informal, pois, segundo se informa, "todos são amigos". A "filosofia" ou as idéias básicas da emprêsa e de seus principais responsáveis são declaradamente "o sentimento de comunidade familiar, a luta, a coragem e o arrôjo do presidente", "elementos galvanizadores da motivação do pessoal na emprêsa". A "produtividade ótima" é encarada como objetivo distante, quase utópico, cuja realização poderá ser conseguida apenas através de aproximações sucessivas e empíricas .

\section{$A$ Emprêsa $B$}

A Emprêsa $B$ é também uma sociedade fechada, propriedade de família. Diferentemente do que ocorre na emprêsa A, nela domina claramente um dos membros da família, que é considerado "gênio técnico, financeiro e comercial" e tem formação superior. Os diretores são membros da família e pràticamente todos têm também formação superior. Os administradores de nível médio-superior (gerentes) são recrutados entre funcionários antigos da emprêsa e também, em alguns casos, entre parentes da família. Pràticamente todos têm formação superior. A emprêsa proporciona - mas raramente - oportunidades de aperfeiçoamento a seus administradores. Nos níveis médio e superior da administração há um "clima" de grande respeito e admiração pelo "líder", o que acentua o caráter de comunidade "patriarcal" da emprêsa.

A emprêsa não tem organograma, e nunca pensou em elaborar um manual da organização ou de procedimentos para os diversos departamentos. 
A comunicação com os superiores hierárquicos é informal, mas não há dúvida de que o "líder" é o grande iniciador de ação e comunicação, falando muito mais do que ouvindo. A "filosofịa" da emprêsa poderia ser resumida no sentido de "comunidade familiar" e de admiração pelo "líder". A "produtividade ótima" reconhecidamente nunca foi encarada como objetivo, nunca estêve em cogitação, em virtude dos problemas mais prementes do dia-a-dia que a emprêsa vive.

\section{A Emprêsa C}

A Emprêsa $C$ é uma sociedade fechada, propriedade de família. Os diretores são membros da família, sem formação superior, "homens da prática que atuaram no setor desde a juventude", cujo treinamento formal se deu na forma de estágios e cursos de treinamento no Brasil e no exterior. Os administradores de nível médio-superior são recrutados de preferência nas escolas superiores e no mercado de trabalho, tendo todos formação técnico-profissional ou superior. (A emprêsa facilita em alguns casos a promoção de funciónărios a posiçōes de chefia.) A emprêsa incentiva $o$ aperfeiçcamento de "seus administradores, recomendando frequiência de seus administradores de nivel médio-superior a cursos de treinamento.

A emprêsa tem organograma, que reflete a estrutura orgânica em funcionamento, e tem manuais de organização e de procedimentos para os diversos departamentos.

A comunicação é feita em reuniôes regulares em todos os setores, desde os níveis de chefia até a diretoria. $\mathrm{Na}$ emprêsa se prefere a comuniçação formal, por escrito, especialmente de assuntos importantes.

Diversas modificações têm sido introduzidas no organograma e na organização a fim de atender à necessidade de melhor definição de autoridade e de campo de ação, assim como de melhoria de métodos e processos . 
A "filosofia" da emprêsa é resumida na necessidade de "enobrecer a produção" e "expandir". A "produtividade ótima" foi definida pela emprêsa como o maior valor da relação "produção/mão-de-obra". Para realizá-la foram citados os seguintes meios: aumento de produção; redução de paradas de maquinismos; aumento máximo de mecanização; redução da mão-de-obra, pela redução do absentismo e pelo aumento de rendimento individual.

\section{A Emprêsa $D$}

A Emprêsa $D$ é uma sociedade fechada, propriedade de família. Os diretores sằo membros da família, de formação superior, e administradores contratados, também de formação superior. Os administradores de nível médio-superior são recrutados na própria emprêsa e no mercado de trabalho, preferindo-se aquêles que tenham formação superior. A emprêsa facilita o aperfeiçoamento de seus administradores, mas não mantém programa formal de treinamento e desenvolvimento.

A emprêsa não tem organograma e nunca elaborou um manual de organização ou de procedimentos para os diversos departamentos. A comunicação é feita em reuniões formais e informais e através de memorandos escritos .

\section{A Emprêsa $E$}

A Emprêsa $E$ é sociedade de capital público. A diretoria (presidente, diretor-financeiro diretor industrial, diretoradministrativo e diretor-comercial) tem sofrido constantes modificações, em virtude do processso de nomeação, constituindo-se quase sempre de profissionais de nivel superior. Os administradores de nível médio-superior são recrutados, em geral, na própria emprêsa, sendo, na maioria, de formação superior.

A emprêsa não tem programa formal e sistemático de treinamento e desenvolvimento de administradores. 
Por fôrça de modificações na organização, não há nela organograma em funcionamento. A comunicação é principalmente formal e por escrito, realizando-se periòdicamente reunióes formais.

\section{A Emprêsa $F$}

A Emprêsa $F$ é uma sociedade fechada, de capital privado estrangeiro. Os diretores são profissionais de nível superior, brasileiros e estrangeiros (presidente, secretário comercial, industrial e tesoureiro). Os administradores de nível médio-superior são recrutados na própria emprêsa e no mercado de trabalho, predorninando entre êles a formação superior.

A emprêsa facilita a promoção de seus empregados a posições dirigentes e, por isso, muitos de seus atuais administradores de nível médio-superior começaram sua carreira em níveis inferiores, na própria emprêsa.

A emprêsa facilita aperfeiçoamento e atualização de seus administradores, mas sem plano sistemático. Concede bôlsas de estudos e estágios em congêneres.

A emprêsa tem organogramas, manual de organização e manuais de procedimento para os diversos departamentos. O organograma está em funcionamento e por diversas vêzes tem sido modificado. A comunicação é principalmente formal, em reuniões periódicas e memorandos ou circulares internas.

\section{A Emprêsa G}

A Emprêsa G é sociedade aberta, de capital privado estrangeiro. Seus diretores são profissionais de nivel superior (presidente, vice-presidente, superintendente e adjuntos) brasileiros e estrangeiros: Os administradores de nível médio-superior são recrutados na própria emprêsa e no mercado de trabalho, preferindo-se profissionais de nível superior. 
A emprêsa tem organograma e manual de organização em funcionamento, que têm sofrido modificações através do tempo. A comunicação é principalmente formal, oral e escrita .

\section{A Emprêsa $H$}

A Emprêsa $H$ é sociedade de capital público. A diretoria (presidente, vice-presidente, diretor-industrial, diretor de matérias-primas, diretor-comercial, diretor-tesoureiro e diretor de pessoal e de serviços sociais) tem sofrido modificações constantes por fôrça do processo de nomeação, constituindo-se, na quase totalidade dos casos, de profissionais de nível superior. Os administradores de nível médio-superior são recrutados na própria emprêsa, nas escolas superiores e médias (neste último caso para os cargos iniciais de carreira) e no mercado de trabalho.

A formação escolar dos administradores de nível médiosuperior é universitária. A emprêsa facilita - e, em parte, pelos critérios de promoção, incentiva - o aperfeiçoamento e a atualização de seus administradores. Além disso, concede bôlsas de estudos para treinamento no país e no exterior e proporciona oportunidade de estágios em congêneres nacionais ou estrangeiras: Por fốrça de seu plano de carreira, a emprêsa tem em seu nível médio-superior administradores que começaram a trabalhar em níveis inferiores na própria emprêsa.

A emprêsa tem organograma em funcionamento, já por diversas vêzes modificado, além de manuais de organização e de procedimentos, e de regulamentos de pessoal e de benefícios .

A comunicação é principalmente formal. A emprêsa entende como conveniente reduzir ao mínimo a comunicação informal.

A emprêsa define "produtividade ótima" como "determinação da capacidade dos equipamentos e medição da produtividade dos diversos fatôres de produção, comparando- 
os com emprêsas similares, com o cuidado necessário no tratamento de dados e alternativas peculiares a cada uma (nacionais e estrangeiras)".

\section{A ORGANIZAÇÃo DA PRODUÇÃo NAS EMPRÊSAS PESQUISADAS}

As características gerais de organização administrativa das oito emprêsas pesquisadas ficarão mais vívidas se fôr examinada a organização da produção que nelas vigora. Infelizmente, faltam-nos dados sôbre êsse aspecto das emprêsas B e E. Acreditamos, porém, que o exame das respostas que recebemos das demais aos quesitos constantes do questionário citado será suficiente para verificarmos a relação entre a organização administrativa das seis emprêsas e suas características e planos de expansão da produção.

\section{Organização da Produção na Emprêsa $A$}

A emprêsa planeja ampliar nos próximos cinco anos a laminação (para $150.000 \mathrm{t}$ de produtos acabados) e a aciaria (para 180.000 t de lingotes). Nesse sentido, de imediato planeja fazer nôvo forno Siemens-Martin de 40 a $50 \mathrm{t}$. (No futuro, talvez instale nôvo forno de lingotagem contínua, que daria para $300.000 \mathrm{t}$ ).

A emprêsa não tem departamento de pesquisas e desenvolvimento de produtos em sentido próprio, mas sim um departamento técnico, de criação recente, com três engenheiros, que cuida da expansão e dos novos produtos. Seus estudos de novos produtos, porém, não visam a "grande coisa no momento" (expressão textual). Apesar disso (que é explicado pelo fato de o lingote de $150 \mathrm{~kg}$ não fornecer produtos de muito boa qualidade), a emprêsa planeja entrar mais tarde na produção de aços especiais.

No tocante ao planejamento e contrôle da produção a emprêsa tem um plano mensal de produção, que funciona da seguinte forma: o chefe do escritório técnico faz o plano; vendas fornece a previsão; o programa é fornecido com vinte dias de antecedência. Mas considera-se que o im- 
portante, na emprêsa, é o programa de laminação mensal, feito numa reunião entre o superintendente da usina, o chefe da laminação e o chefe do escritório técnico.

Em relação ao contrôle de qualidade a emprêsa tem um laboratório muito modesto. Não possui laboratório metalográfico. Um engenheiro-chefe está à frente do departamento de contrôle de qualidade, servindo a tôda a usina.

A emprêsa não tem um departamento de engenharia industrial e reconhece que êsse departamento faz muita falta.

Quanto a estudos especiais em pesquisa operacional, programação linear e outras aplicações quantitativas na administração da produção, a emprêsa revelou que foi aplicado sòmente o PERT na construção.

\section{Organização da Produção na Emprêsa C}

A emprêsa planeja instalar nos próximos cinco anos (1965-1970) nova laminação e aciaria numa de suas usinas. Em outra reequipou completamente a seção de fundição, que ficou aparelhada para produzir $6.000 \mathrm{t}$ de fundidos especiais pelo processo Mechanite. Além disso, planeja reequipar sua estamparia, que produz grampos e parafusos para trilhos.

A emprêsa não tem departamento de pesquisa e desenvolvimento de produtos'. Para isso, participa de uma emprêsa de estudos e projetos que lhe presta assistência, quando necessária. De qualquer forma, as idéias sôbre pesquisas e desenvolvimento de novos produtos são dos diretores.

A seção de vendas trabalha em conjunto com a produção, sendo feitos programas mensais e trimestrais de produção. A emprêsa, entretanto, não tem um departamento de planejamento e contrôle da produção - tem, isso sim, um laboratório em cada usina para contrôle da produção. $\mathrm{Na}$ emprêsa não se acredita que as vendas possam ser plajadas com precisão. 
No tocante ao contrôle de qualidade a emprêsa tem em cada fábrica um engenheiro de produção e na matriz um diretor técnico. A emprêsa não tem um engenheiro de qualidade "por ser pequena", sendo a qualidade de alçada do engenheiro de produção.

Não há departamento de engenharia industrial e foi usado, na administração da produção, dentre os métodos quantitativos, o PERT.

\section{Organização da Produção na Emprêsa $D$}

Os planos de expansão de instalações para os próximos cinco anos (1965-1970) na emprêsa D são: construção e instalação de uma aciaria LD com capacidade para $120.000 \mathrm{t}$ /ano e de um alto forno com capacidade para $120.000 \mathrm{~kg} / \mathrm{dia}$, e colocação em funcionamento de um laminador para perfis leves.

A emprêsa não tem departamento especializado de pesquisas e desenvolvimento de produtos, "pois não acha necessária a criação dêsse setor na organização". Para o planejamento de novos produtos a emprêsa se baseia nos diversos levantamentos efetuados por órgãos governamentais sôbre a previsão da demanda de aço no mercado.

O planejamento da produção é elaborado pelo departamento comercial da emprêsa, que efetua a programação mensal da produção de acôrdo com os pedidos em carteira. Êsse programa é encaminhado à usina para cumprimento, mas nela não há departamento de planejamento e contrôle de produção.

O departamento de contrôle de qualidade é subdividido em dois setores principais: laboratório químico e laboratório de ensaios mecânicos. Os materiais sòmente são expedidos depois de devidamente aprovados por êsse setor.

A emprêsa não tem departamento de engenharia industrial. Cada setor da fábrica é chefiado por um engenheiro subordinado diretamente ao diretor industrial. 
A emprêsa não realizou quaisquer estudos em pesquisa operacional, programação linear e outros métodos quantitativos na administração de produção.

\section{Organização da Produção na Emprêsa $F$}

Para os próximos cinco anos (1965-1970) a emprêsa planeja instalar fundição contínua e laminação de perfis finos e médios.

A emprêsa tem um serviço de processamento metalúrgico, subordinado ao departamento de contrôle de qualidade, para pesquisa e desenvolvimento de produtos.

Cada usina da emprêsa mantém um setor estanque de planejamento da produção, sendo a coordenação geral feita diretamente pelo diretor industrial e seus assistentes. $O$ contrôle da produção faz parte de um departamento staff da diretoria industrial, o departamento de economia técnica.

O departamento de contrôle de qualidade da emprêsa está dividido em: serviço de inspeção (composto de um laboratório mecano-tecnológico e de um setor de contrôle de produtos), serviço de laboratório químico e serviço de consultas técnicas.

O órgão que na emprêsa corresponde à engenharia industrial é o departamento de economia técnica, que está dividido em três serviços: fluxo da produção; organização do trabalho; e estudos econômicos .

A emprêsa declara ter feito estudos de pesquisa operacional através do serviço de estudos econômicos do departamento de economia técnica, com a colaboração da matriz estrangeira.

Organização da Produção na Emprêsa G

A emprêsa planeja a seguinte expansão de instalações: construção de nova sinterização tipo Greenewalt; construção de alto-forno a carvão vegetal; instalação do nôvo 
convertedor LD de $35 \mathrm{t}$; instalação de novos fornos Pits; instalação de trem de arame Morgan; e ampliação da trefilaria .

As pesquisas e os estudos de desenvolvimento de produtos são realizados pela divisão de vendas sob a orientação de um engenheiro.

A programação de produção na emprêsa é feita com base em encomendas bimensais. No fim do período a programação é confrontada com a produção realizada.

O departamento de contrôle de qualidade da emprêsa inclui: laboratório químico, laboratório de metalografia, seção térmica, seção de pesquisas, seção de contrôle metalúrgico, seção das operações de produção e seção de contrôle de qualidade.

A emprêsa está organizando um departamento de engenharia industrial e planeja estudos de pesquisa operacional na administração da produção.

\section{Organização da Produção na Emprêsa $H$}

A emprêsa tem elaborado minucioso plano de expansão, segundo o qual planeja triplicar em dez anos (1965-1975) sua produção atual de aço em lingotes. Para tanto pretende não só instalar grande número de equipamentos de produção, como também expandir outros setores, tais como os de manutenção, transportes, fundição, contrôle de qualidade, administração, etc .

O departamento de pesquisas e desenvolvimento de produtos da emprêsa tem um setor de pesquisas metalúrgicas e outro de pesquisas químicas, contando ambos com laboratórios para pesquisa aplicada.

O departamento de planejamento e contrôle de produção é subordinado à diretoria industrial e tem as seguintes divisões: planejamento da produção, estatística e contrôle, e ordens de produção. 
A linha de contrôle de qualidade está dividida em três departamentos: de processos; de inspeção; e de contrôle químico.

A engenharia industrial está dividida em três departamentos: organização do trabalho; métodos e incentivos; e estudos industriais.

A emprêsa tem realizado vários estudos com a utilização de métodos quantitativos na administração da produção, por exemplo, na determinação do tempo ótimo de campanha de forno de aço, na simulação de número de corridas para cálculo de pontes-rolantes e na reforma de um altoforno.

ALGUMAS CONCLUSŌES SÔBRE A ORGANIZAÇÃO DAS EMPRESAS

As Emprêsas $A, B, C$ e $D$ têm em comum não só a origem do capital, que é privado nacional, como também muitas de suas facêtas como organização: tôdas elas foram criadas em circunstâncias fortuitas, pela reunião de condições favoráveis que possibilitaram seu desenvolvimento inicial; tôdas elas foram - ou ainda são - dirigidas por verdadeiros entrepreneurs, no sentido schumpeteriano do têrmo; tôdas elas vivem a braços com o problema de falta de recursos para expansão rápida; tôdas elas têm falta de integração entre seus setores produtivos, com conseqüentes problemas de estrangulamento e capacidade ociosa de produção .

Não é, portanto, estranhável que sejam tôdas elas pequenas emprêsas, dirigidas pela família proprietária e por pessoas de sua confiança com grande dedicação e cuidado, caracterizando-se por centralização de autoridade nos níveis superiores da organização, por falta de departamentalização planejada e de divisão equilibrada de funções entre os diversos departamentos e por treinamento assistemático de administradores .

Cumpre destacar, porém, algumas características administrativas que vigoram em pelo menos uma das pequenas emprêsas de capital privado nacional na Emprêsa $C$, já há 
organograma e manual de organização e procedimentos em funcionamento; nela já se faz procura regular de aciministradores de alto gabarito no mercado de trabalho (e não sòmente de pessoal técnico, como ocorre nas três outras); enfim, nela já há a preocupação de "profissionalizar" a administração, com conseqüente procura de "burocratização" no bom sentido, eliminando-se a influência pessoal junto à familia proprietária como forma de acesso aos escalóes superiores.

É bom observar também que na Emprêsa $D$ já há condições, atualmente, para que desenvolvimento semelhante ao que vem ocorrendo na Emprêsa $C$ ali tenha lugar.

Quanto às emprêsas de capital privado estrangeiro, convém destacar o caráter integrado e racionalmente planejado da emprêsa $F$ e, apesar do acidentado crescimento desde sua criação há mais de quarenta anos, da procura de eficiência da Emprêsa $G$. Ambas são emprêsas em que a profissionalização de diretores e gerentes de nível médiosuperior é a norma e ambas procuram incentivar constantemente o aperfeiçoamento e a atualização de administradores .

Finalmente, no tocante às emprêsas de capital público nacional, convém distinguir as condições de crescimento e operação da emprêsa $E$, que é pequena emprêsa de história acidentada e de crescimento não planejado a longo prazo, das da emprêsa $\mathrm{H}$, que foi criada como um grande projeto, até hoje funcionando com equipamento balanceado (e "cotas" departamentais de produção predeterminadas que não "precisam" ser ultrapassadas). A emprêsa E não está organizada de forma racional. Mas a emprêsa $H$ vem procurando racionalizar sua administração, adotando as técnicas modernas de avaliação de cargos, de administração de pessoal, de planejamento e contrôle da produção etc. Em alguns aspectos, essa grande emprêsa tende à burocratização no mau sentido, com acúmulo de comunicações rotineiras e complexidade excessiva, por exemplo, em seus organcgramas. Mas pela soma de recursos que reúne e pela escala em que opera, essa é certamente a emprêsa que, den- 
tre as examinadas, mais avançada se encontra em matéria de organização administrativa .

No setor de produção, vimos que as emprêsas, sem exceção, planejam modernizar, expandir e melhorar seu equipamento produtivo. Os planos de expansão de instalações vão, entretanto, desde os mais modestos das pequenas emprêsas até os ambiciosos, especialmente da maior emprêsa do grupo pesquisado. A diferença básica na organização da produção, porém, está na departamentalização, pois nas emprêsas médias e grandes a especialização já se verifica, enquanto que, nas menores, ainda não é considerada "necessária".

Na prática, sòmente as emprêsas de maior porte têm os recursos financeiros e humanos para pôr em funcionamento uma organização no estilo moderno. Por isso é que é especialmente interessante a procura de organização racional realizada por emprêsas como $\mathrm{C}$ e $\mathrm{D}$, que, apesar de enfrentarem problemas mais prementes do dia-a-dia, já imaginam poder aparelhar-se para o desenvolvimento futuro, garantindo, assim, em parte, êsse mesmo desenvolvimento.

Finalmente, é de notar que, para as emprêsas pequenas e médias pesquisadas, os objetivos mais constantes no sentido da expansão da produção são a ampliação da laminação e da aciaria, além da produção de perfis leves e médios, certamente porque parecem estar aí exatamente suas maiores possibilidades de mercado e, portanto, de sobrevivência e concorrência .

A conclusão sôbre as condições de concorrência e crescimento da indústria siderúrgica nacional, com base nas emprêsas pesquisadas e à luz das informações obtidas sôbre seus aspectos de administração e produção, não pode ser senão de expectativa otimista. Mas não podemos deixar de notar que as menores emprêsas certamente deverão passar por transformações radicais de estilo e métodos administrativos para poderem sobreviver, e que as maiores ainda têm muito a racionalizar nesse aspecto antes de consolidarem a posição já conquistada pelo País no setor siderúrgico. 